\title{
Endogenous Choice of Managerial Incentives in a Mixed Duopoly with a Foreign Private Firm
}

\author{
Kadohognon Sylvain Ouattara \\ Esca Ecole de Management, Casablanca, Morocco \\ Email: kadohognon.ouattara@unicaen.fr, kouattara@esca.ma
}

Received 24 February 2016; accepted 24 April 2016; published 27 April 2016

Copyright (C) 2016 by author and Scientific Research Publishing Inc. This work is licensed under the Creative Commons Attribution International License (CC BY). http://creativecommons.org/licenses/by/4.0/ cC) (7) Open Access

\begin{abstract}
This paper studies the endogenous choice of managerial incentives in a mixed duopoly where a public firm competes with a foreign private firm. The foreign firm is partly owned by domestic investors and the firm's owners have the option to hire a manager. We focus on a new incentive scheme of public firm's managers that is a linear combination of social welfare and sales revenue. In equilibrium we find that when the weight attached to the foreign firm's profits in social welfare is high enough, only the public firm hires a manager. This is in contrast with the classical sales delegation contract used in existing literature.
\end{abstract}

\section{Keywords}

Public Firm, Foreign Private Firm, Strategic Delegation, Mixed Duopoly, Cournot Model

\section{Introduction}

In most countries, many industries are characterized by the simultaneous presence of public firm and foreign private firm (energy, airlines, tobacco, ...). There are numerous papers that analyze the interaction between public and private firms. However, most of these papers suppose that the private firm is either totally owned by domestic investors (De Fraja et Delbono [1]; Matsumura [2]; Ohori [3]), either totally owned by foreign investors (Fjell and Pal [4]). In this paper, we consider the intermediate situations between the cases of full domestic ownership of the private firm and full foreign ownership of the private firm. In these situations, a proportion of the profits of the foreign private firm are transferred out of the public firm's home country. Thus, it is worthwhile to examine the presence of partial foreign ownership firm because the welfare does not include the whole foreign private profits. 
Furthermore, in this paper, we focus a mixed duopoly with incentive contracts for managers. The literature on strategic delegation, which started with Fershtman and Judd [5], and Sklivas [6], supposes that the owners of private firms provide a delegation contract for their managers, which is a linear combination of profits and sales (the so-called FJS contracts). Previous studies on strategic delegation in mixed oligopoly suppose that both the public and private firms provide managers a FJS contract (Barros [7]; White [8]; Fernandez-Ruiz [9]). In this paper, we focus on the situation wherein the public firm incentive scheme takes into account the social welfare. So the public firm's owner offers its manager an incentive contract that is a linear combination of social welfare and the public firm's sales revenue, and the private firm's owners provide managers a FJS contract. In this context, we pose the following question: How does the weight attached to the foreign firm's profits in social welfare affect the endogenous decision of hiring managers?

As for studies with motivation similar to ours, we have Fernandez-Ruiz [9] who considers the impact of weight attached to the foreign firm's profits in a mixed duopoly with delegation. However, Fernandez-Ruiz [9] considers a sale delegation contract (FJS contract) for both the public and private firms.

We show that the decision to hire managers depends on the weight associated to the foreign firm's profit in social welfare. If this weight is low enough, both the public firm and the foreign private firm hire managers. If this weight is high enough, only the public firm hires managers. This last result is in contrast with that obtained when owners provide to their managers a FJS contract, where only the foreign private firm hires managers in equilibrium (Fernandez-Ruiz [9]). Moreover, we find that social welfare increases if firms hire managers.

\section{The Model}

We consider a mixed duopoly model with one state-owned public firm (denoted by 0 ) and one foreign private firm (denoted by 1). The foreign private firm is jointly owned by domestic and foreign shareholders. The inverse demand function is given by: $p=1-Q$, where $Q$ is the total output of the good $\left(Q=q_{0}+q_{1}\right)$. We assume that both firms have identical technology represented by the quadratic cost function $C\left(q_{i}\right)=\frac{1}{2} q_{i}^{2}$. The owners of firm 1 aim to maximize the firm's profits. Firm i's profit is denoted by:

$$
\pi_{i}=p q_{i}-\frac{1}{2} q_{i}^{2} \quad(i=0,1)
$$

The public firm's owners aim to maximize social welfare, defined as the sum of the consumer surplus, the profits of the public firm, and a proportion $\gamma \in[0,1]$ of the profits of the foreign private firm (Fernandez-Ruiz [3]).

$$
W=\frac{Q^{2}}{2}+\pi_{0}+\gamma \pi_{1}
$$

If $\gamma=0$, firm 1's profits are excluded from social welfare and if $\gamma=1$, the whole firm 1's profits are included in social welfare.

Furthermore, our paper focuses on the managerial aspect of the firms. Owners of firm $i$ can hire a manager to make his firm's production decisions. Private firm's owners offer their manager an incentive contract that is a linear combination of profit and sales revenue (FJS contract):

$$
M_{1}=\lambda_{1} \pi_{1}+\left(1-\lambda_{1}\right) p q_{1}
$$

where $\lambda_{1}$ is the incentive parameter that the owners of private firm choose to maximize their profit.

The public firm's owners offer its manager an incentive contract that is a linear combination of welfare $(W)$ and sales revenue:

$$
M_{0}=\lambda_{0} W+\left(1-\lambda_{0}\right) p q_{0}
$$

where $\lambda_{0}$ is the incentive parameter that the owners of public firm choose to maximize their objective. Note that if $\lambda_{i}=1$, manager of firm i's behavior coincides with owner $i$ 's objective.

The game that we consider in this paper runs as follows. In the first stage, the owners of the firms decide whether or not to hire a manager. In the second stage, if they have hired a manager, each owner sets the corresponding managerial incentives parameter $\lambda_{i}$. In the final and third stage, managers compete $a$ là Cournot. We adopt a subgame perfect Nash equilibrium and thus, the game is solved backwards. 


\section{Results}

We start the game by solving the third and second stage.

\subsection{Manager's Competition and Optimal Incentive Schemes}

Given that the owner of each firm may hire a manager or not, there are four possible cases: both firms hire managers (denoted by superscript DD), neither firm hires a manager (denoted by superscript NN), only the foreign private firm hires a manager (denoted by superscript ND) and only the public firm hires a manager (denoted by superscript DN).

\subsubsection{Both Firms Hire Managers (DD)}

In this case, there is a manager at each firm. In the third stage, the public firm's manager and the foreign private firm's manager choose the output that maximizes respectively (4) and (3). Solving these problems, we obtain:

$$
q_{0}=\frac{\lambda_{0}+2 \lambda_{1}-\gamma \lambda_{0}+1}{\lambda_{0}+4 \lambda_{1}-\gamma \lambda_{0}+3}, q_{1}=\frac{1}{\lambda_{0}+4 \lambda_{1}-\gamma \lambda_{0}+3} .
$$

At stage two, the owners of the foreign private firm and the owners of public firm choose simultaneously $\lambda_{1}$ and $\lambda_{0}$ that maximizes respectively (1) and (2). We obtain:

$$
\begin{gathered}
\lambda_{0}^{D D}=1-\frac{3-\sqrt{\gamma^{2}+7}}{1-\gamma}, \quad \lambda_{1}^{D D}=1-\frac{5+\gamma-\sqrt{\gamma^{2}+7}}{4}<1 \\
q_{0}^{D D}=\frac{3\left(-1-\gamma+\sqrt{\gamma^{2}+7}\right)}{4\left(\sqrt{\gamma^{2}+7}-\gamma\right)}, q_{1}^{D D}=\frac{1}{2\left(\sqrt{\gamma^{2}+7}-\gamma\right)}, Q^{D D}=\frac{3\left(\sqrt{\gamma^{2}+7}-\gamma\right)-1}{4\left(\sqrt{\gamma^{2}+7}-\gamma\right)} \\
\pi_{0}^{D D}=\frac{3}{16} \frac{(\gamma+3) \sqrt{\gamma^{2}+7}-\gamma(\gamma+3)-6}{2 \gamma\left(\gamma-\sqrt{\gamma^{2}+7}\right)+7}, \pi_{1}^{D D}=\frac{1}{8\left(\sqrt{\gamma^{2}+7}-\gamma\right)}, W^{D D}=\frac{1}{8} \frac{(3-2 \gamma)\left(\sqrt{\gamma^{2}+7}-\gamma\right)+7}{\left(\gamma-\sqrt{\gamma^{2}+7}\right)^{2}} .
\end{gathered}
$$

In equilibrium, we observe that the owners of the foreign private firm always encourage their manager to produce more than a profit maximizer firm $\left(\lambda_{1}^{D D}<1\right)$. The public manager's incentive parameter is less than one, and may be negative if the weight attached to the foreign firm's profits is high enough $(\gamma>0.75)$. Moreover, when $\gamma$ increases, both incentive parameters $\lambda_{0}^{D D}$ and $\lambda_{1}^{D D}$ decrease.

\subsubsection{Neither Firm Hires a Manager (ND)}

In the third stage, the public and foreign private firms choose simultaneously their outputs to maximize their objective functions, given respectively by (2) and (1). Solving these problems, we obtain:

$$
\begin{gathered}
q_{0}^{N N}=\frac{3-\gamma}{6-\gamma}, q_{1}^{N N}=\frac{1}{6-\gamma}, Q^{N N}=\frac{4-\gamma}{6-\gamma} \\
\pi_{0}^{N N}=\frac{(\gamma+1)(3-\gamma)}{2(\gamma-6)^{2}}, \pi_{1}^{N N}=\frac{3}{2(\gamma-6)^{2}}, W^{N N}=\frac{19-3 \gamma}{2(\gamma-6)^{2}} .
\end{gathered}
$$

\subsubsection{Only the Foreign Private Firm Hires a Manager (ND)}

In the third stage, the manager of the foreign private firm and the owner of the public firm choose their firm's output in order to maximize their objective function given respectively by (3) and (2). Solving these problems, we obtain:

$$
q_{0}=\frac{\lambda_{1}-\gamma+2}{2 \lambda_{1}-\gamma+4}, q_{1}=\frac{1}{2 \lambda_{1}-\gamma+4} .
$$

At the second stage, the owners of the foreign private firm choose $\lambda_{1}$ that maximizes (1). This results in: 


$$
\begin{gathered}
\lambda_{1}^{N D}=1-\frac{1}{2} \gamma<1, q_{0}^{N D}=\frac{3(2-\gamma)}{4(3-\gamma)}, q_{1}^{N D}=\frac{1}{2(3-\gamma)}, Q^{N D}=\frac{8-3 \gamma}{4(3-\gamma)} \\
\pi_{0}^{N D}=\frac{3(2-\gamma)(2+\gamma)}{32(\gamma-3)^{2}}, \pi_{1}^{N D}=\frac{1}{8(3-\gamma)}, W^{N D}=\frac{-18 \gamma+\gamma^{2}+38}{16(\gamma-3)^{2}} .
\end{gathered}
$$

\subsubsection{Only the Public Firm Hires a Manager (DN)}

In the third stage, the manager of the public firm and the owners of the foreign private choose their firm's output in order to maximize their objective function given respectively by (4) and (1). Solving these problems, we obtain:

$$
q_{0}=\frac{\lambda_{0}-\gamma \lambda_{0}+2}{\lambda_{0}-\gamma \lambda_{0}+5}, q_{1}=\frac{1}{\lambda_{0}-\gamma \lambda_{0}+5} .
$$

At the second stage, the owner of the public firm chooses $\lambda_{0}$ that maximizes (3). We obtain:

$$
\begin{gathered}
\lambda_{0}^{D N}=1-\frac{1}{3(1-\gamma)}, q_{0}^{D N}=\frac{8-3 \gamma}{17-3 \gamma}, q_{1}^{D N}=\frac{3}{17-3 \gamma}, Q^{D N}=\frac{11-3 \gamma}{17-3 \gamma} \\
\pi_{0}^{D N}=\frac{(3 \gamma+4)(8-3 \gamma)}{2(3 \gamma-17)^{2}}, \pi_{1}^{D N}=\frac{27}{2(3 \gamma-17)^{2}}, W^{D N}=\frac{9}{2(17-3 \gamma)} .
\end{gathered}
$$

\subsection{Owners' Decisions How to Whether or Not Hire a Manager}

In the first stage of the game, the owner of each firm decides whether or not to hire managers. The solution is given in the following proposition.

Proposition 1. In equilibrium,

- both the public firm and the foreign private firm hire a manager, if $\gamma \leq \gamma^{*}$;

- only the public firm hires a manager, if $\gamma>\gamma^{*}$.

$$
\gamma^{*}=0.889
$$

Proof: See Appendix 1.

The above result shows that in equilibrium the decision to hire managers depends on the weight attached to the foreign firm's profits $(\gamma)$. In fact, it is a dominant strategy for the public firm to hire a manager

$\left(W^{D D}>W^{N D}, W^{D N}>W^{N N}\right)$. Independently of whether the private firm hires a manager or not, the public firm hires a manager because the decrease in the consumer surplus has a lower effect on welfare than the increase in the domestic producer surplus. When the public firm hires a manager, the foreign private firm does not hire a manager if the weight attached to his profits is high enough $\gamma>\gamma^{*}$. When $\gamma \leq \gamma^{*}$ the private firm profit's is higher if it hires a manager.

This result is in contrast with that obtained by Fernandez-Ruiz [9]. Fernandez-Ruiz [9] supposes that both, foreign and public firms assign a FJS managerial contract to their manager. He shows that in equilibrium, if the weight attached to the foreign firm's profits is high enough, only the private firm hires a manager. The difference in results between our paper and Fernandez-Ruiz [9] is mainly explained by the form of managerial contracts. Assigning a FJS contract for the public manager provide no strategic advantage for public firm, because the maximization of a linear combination of profits and revenues is qualitatively different from welfare maximization. While with a new managerial contract for the public firm that we purpose, the public firm's manager can see consumer surplus and a part of the foreign private firm profit. Therefore, this new managerial contract provides a strategic advantage for the public firm.

Next, we compare the equilibrium social welfare values with a situation in which neither firm hires a manager.

Proposition 2. In equilibrium, delegation always increases social welfare.

Proof: See Appendix 2.

This proposition shows that in a mixed duopoly equilibrium, social welfare increases when 1) only the public firm hires a manager, and 2) both firms hire managers. In fact, in both cases, the delegation leads to a decrease 
of public firm's output and an increase in private firm's output. Social welfare increases because the loss in consumer surplus is offset by the increase of domestic producer surplus. Note that when both firms hire managers, delegation may increase consumer surplus for $\gamma>0.516$.

\section{Conclusion}

This paper investigates the endogenous decision to hire manager when a public firm competes with a private firm who is partly owned by foreign investors. We supposed that the classical sales delegation contract is employed in the private firm whereas the incentive scheme of public firm's manager takes into account the social goals of public authority. In equilibrium we have found that when the weight attached to the foreign firm's profits in social welfare is high enough, only the public firm hires a manager. This result is in contrast with that obtained when both firms (the public and foreign private) provide a sales delegation contract to their managers.

\section{References}

[1] De Fraja, G. and Delbono, F. (1989) Alternative Strategies of a Public Enterprise in Oligopoly. Oxford Economic Papers, 41, 302-311.

[2] Matsumura, T. (1998) Partial Privatization in Mixed Duopoly. Journal of Public Economics, 70, 473-483. http://dx.doi.org/10.1016/S0047-2727(98)00051-6

[3] Ohori, S. (2014) Price and Quantity Competition in a Mixed Duopoly with Emission Tax. Theoretical Economics Letters, 4, 133-138. http://dx.doi.org/10.4236/tel.2014.42020

[4] Fjell, K. and Pal, D. (1996) A Mixed Oligopoly in the Presence of Foreign Private Firms. Canadian Journal of Economics, 29, 737-743. http://dx.doi.org/10.2307/136260

[5] Fershtman, C. and Judd, K.L. (1987) Equilibrium Incentives in Oligopoly. American Economic Review, 77, $927-940$.

[6] Sklivas, S. (1987) The Strategic Choice of Managerial Incentives. Rand Journal of Economics, 18, 452-458. http://dx.doi.org/10.2307/2555609

[7] Barros, F. (1995) Incentive Schemes as Strategic Variables: An Application to a Mixed Duopoly. International Journal of Industrial Organization, 13, 373-386. http://dx.doi.org/10.1016/0167-7187(94)00461-A

[8] White, M.D. (2001) Managerial Incentives and the Decision to Hire Managers in Markets with Public and Private.

[9] Fernandez-Ruiz, J. (2009) Managerial Delegation in a Mixed Duopoly with a Foreign Competitor. Economics Bulletin, 29, 90-99. 


\section{Appendix}

\section{Appendix 1: Proof of Proposition 1 (Figure A1 and Figure A2)}

- When the private firm does not hire a manager, the public firm hires a manager

$$
W^{D N}-W^{N N}=\frac{1}{2(17-3 \gamma)(\gamma-6)^{2}}>0 .
$$

- When the private firm hires a manager, the public firm does not hire a manager

$$
W^{D D}-W^{N D}=\frac{1}{16} \frac{\gamma\left(3 \gamma+6 \gamma^{2}+2 \gamma^{3}-12\right)-2 \sqrt{\gamma^{2}+7}\left(-2 \gamma+3 \gamma^{2}+\gamma^{3}-27\right)-140}{(\gamma-3)^{2}\left(2 \gamma^{2}-2 \gamma \sqrt{\gamma^{2}+7}+7\right)}>0 .
$$

So hiring manager is a dominant strategy for the public firm.

- When the public firm hires a manager, the private firm:

0 hires a manager if $\gamma \leq \gamma^{*}$.

0 does not hire a manager if $\gamma>\gamma^{*}$.

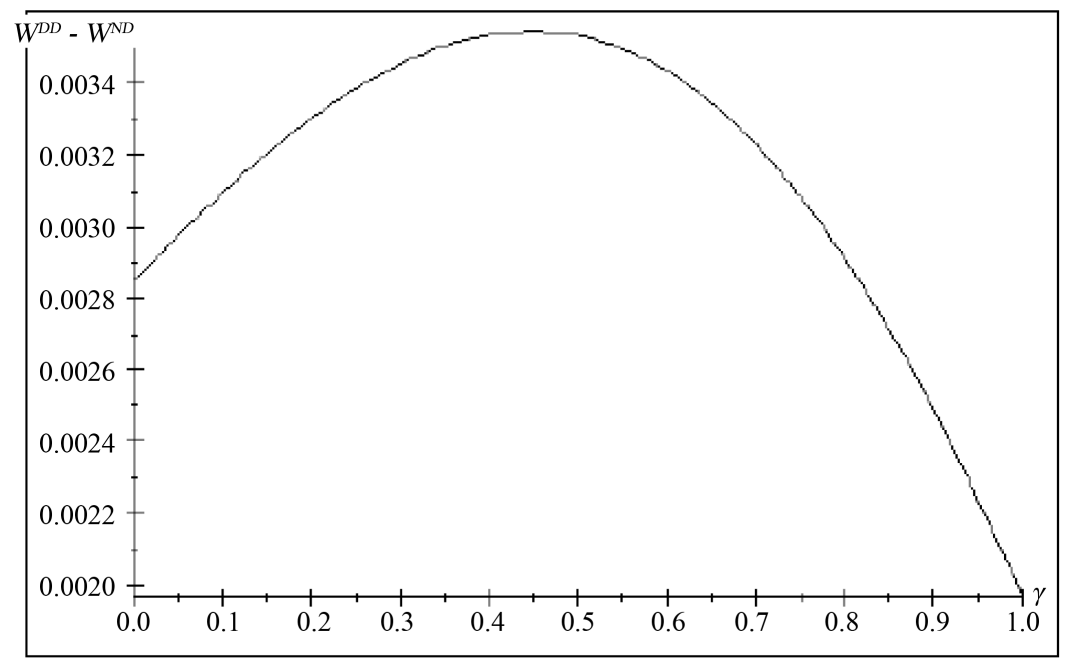

Figure A1. $W^{D D}-W^{N D}$.

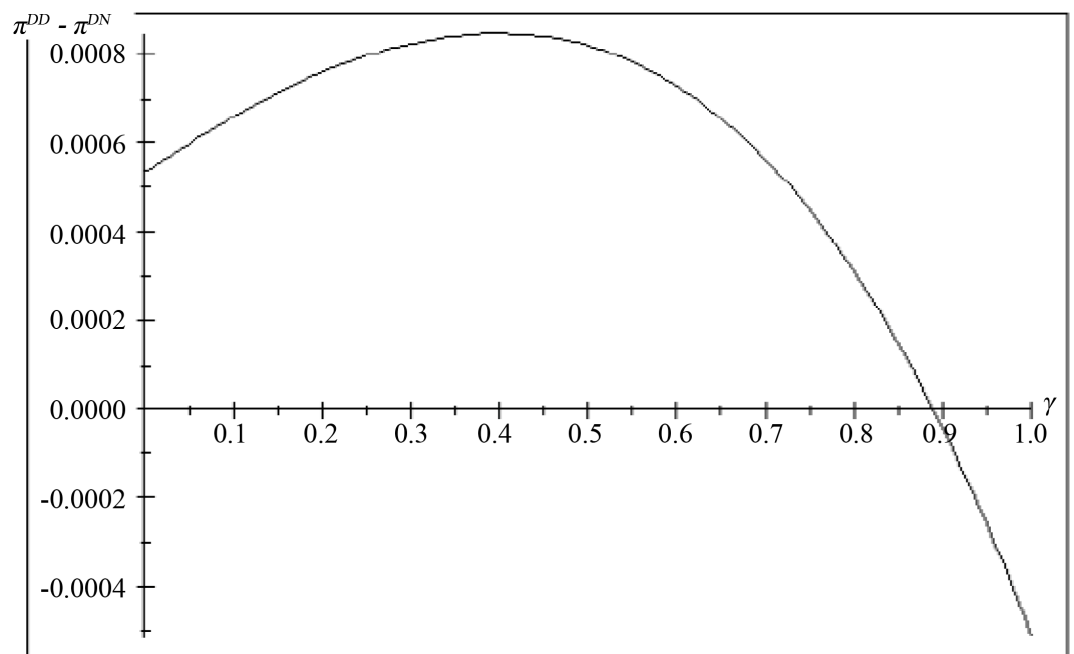

Figure A2. $\pi_{1}^{D D}-\pi_{1}^{D N}$. 


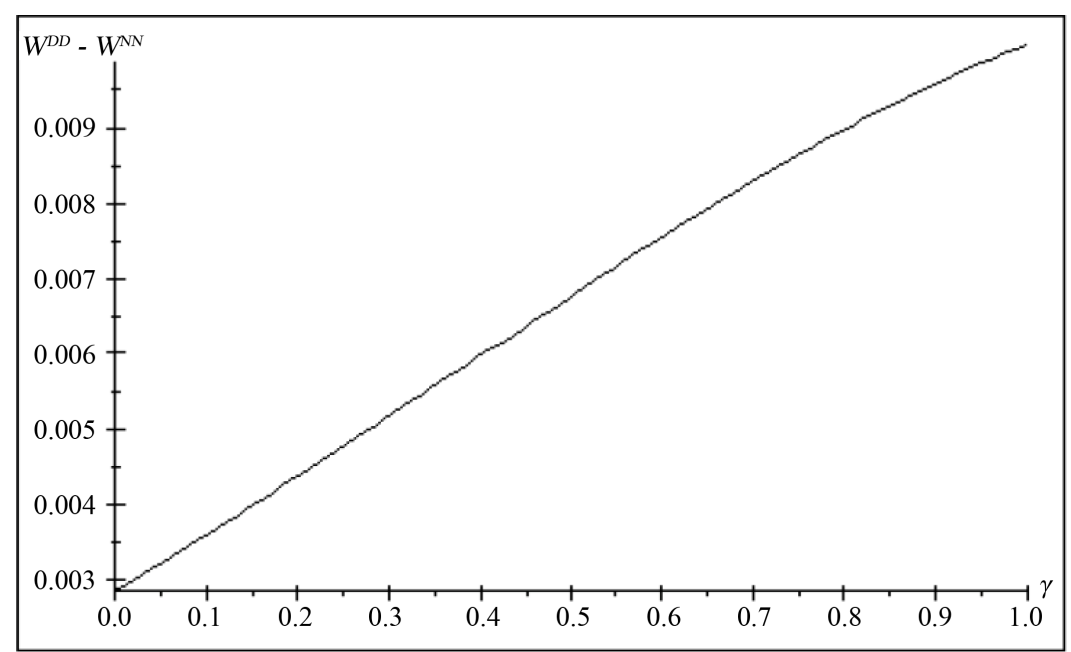

Figure A3. $W^{D D}-W^{N N}$.

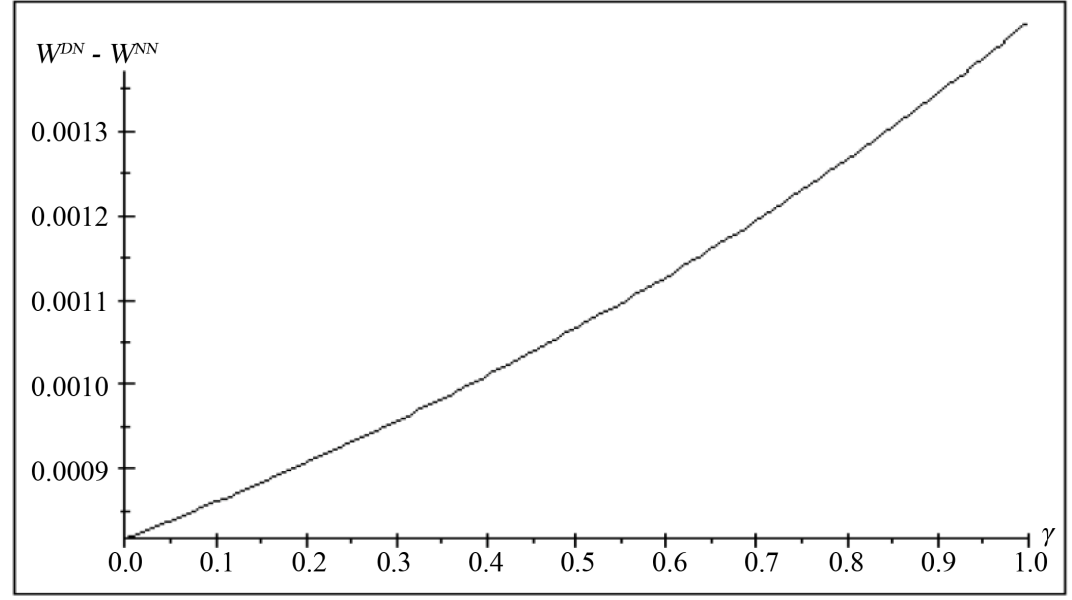

Figure A4. $W^{D N}-W^{N N}$.

with $\gamma^{*}=0.8895246$

$$
\pi_{1}^{D D}-\pi_{1}^{D N}=\frac{1}{8} \frac{3 \gamma(3 \gamma+2)-108 \sqrt{\gamma^{2}+7}+289}{(3 \gamma-17)^{2}\left(\sqrt{\gamma^{2}+7}-\gamma\right)}
$$

Appendix 2: Proof of Proposition 2 (Figure A3 and Figure A4)

$$
\begin{gathered}
W^{D D}-W^{N N}=\frac{1}{8} \frac{\gamma\left(-37 \gamma-3 \gamma^{2}+2 \gamma^{3}-108\right)+\left(44 \gamma+3 \gamma^{2}-2 \gamma^{3}+108\right) \sqrt{\gamma^{2}+7}-280}{(\gamma-6)^{2}\left(2 \gamma^{2}-2 \gamma \sqrt{\gamma^{2}+7}+7\right)}>0 \\
W^{D N}-W^{N N}=\frac{1}{2(17-3 \gamma)(\gamma-6)^{2}}>0
\end{gathered}
$$

